\title{
Algoritma Epsilon Greedy pada Reinforcement Learning untuk Modulasi Adaptif Komunikasi Vehicle to Infrastructure (V2I)
}

\section{NAZMIA KURNIAWATI ${ }^{1}$, YULI KURNIA NINGSIH ${ }^{2}$, SOFIA DEBI PUSPA ${ }^{3}$, TRI SWASONO ADI ${ }^{4}$}

\author{
1,2,4]urusan Teknik Elektro, Universitas Trisakti, Indonesia \\ 3Jurusan Teknik Mesin, Universitas Trisakti, Indonesia \\ Email : nazmia.kurniawati@trisakti.ac.id
}

Received 5 April 2021 | Revised 24 April 2021 | Accepted 3 Mei 2021

\begin{abstract}
ABSTRAK
Komunikasi Vehicle to Infrastructure (V2I) memungkinkan kendaraan dapat terhubung ke berbagai macam infrastruktur. Dengan kondisi kendaraan yang bergerak, maka kondisi lingkungan yang dilewati mempengaruhi parameter komunikasi. Implementasi modulasi adaptif pada skema V2I memperbolehkan sistem menggunakan skema modulasi yang berbeda untuk mengakomodasi perubahan kondisi lingkungan. Pada penelitian ini digunakan skema modulasi QPSK, 8PSK, dan 16-QAM dengan memanfaatkan reinforcement learning dan algoritma epsilon greedy untuk menentukan skema modulasi yang digunakan berdasarkan level AWGN. Dari hasil simulasi dengan kondisi nilai epsilon yang divariasikan dari 0.1 hingga 0.5 didapatkan bahwa semakin tinggi nilai epsilon maka semakin sering agen tidak memilih skema modulasi dengan reward tertinggi.
\end{abstract}

Kata kunci: Reinforcement learning, Modulasi Adaptif, AWGN

\begin{abstract}
Vehicle to Infrastructure (V2I) communication allows vehicles to be connected to various infrastructures. Under the scenario of a moving vehicle, the environmental conditions which is passed by the vehicle will affect the communication parameters. The adaptive modulation implementation in the V2I scheme allows the system to use different modulation schemes to accommodate changing environmental conditions. In this study, the QPSK, 8PSK, and 16-QAM modulation schemes were used by utilizing reinforcement learning and the epsilon greedy algorithm to determine the modulation scheme used based on AWGN level. From the simulation results with the conditions of the epsilon value varying from 0.1 to 0.5 , it is found that the higher the epsilon value, the more often the agent does not choose the modulation scheme with the highest reward.
\end{abstract}

Keywords: Reinforcement learning, Adaptive Modulation, AWGN 


\section{PENDAHULUAN}

Sistem transportasi cerdas merupakan bagian penting dalam pengembangan sebuah kota cerdas (smart city) (Halegoua, 2020). Pada sistem transportasi cerdas, kendaraan dapat berkomunikasi dengan berbagai infrastruktur atau kendaraan lain. Vehicle-to-Infrastructure (V2I) communication merupakan salah satu bagian dari sistem komunikasi pada sistem transportasi cerdas. Pada V2I, kendaraan dapat berkomunikasi dengan infrastruktur di sekelilingnya seperti lampu lalu-lintas, kamera pengawas, atau infrastruktur pada suatu bangunan (Wietfeld \& Ide, 2015). Dengan memanfaatkan kanal wireless, informasi dikirimkan melalui jaringan ad-hoc sehingga proses pertukaran informasi dapat dilakukan secara fleksibel. Melalui sistem ini, kendaraan dan infrastruktur dapat saling bertukar informasi mengenai time of arrival kendaraan, informasi ketersediaan parkir pada gedung, iklan suatu produk, informasi navigasi dan lalu lintas (Cronin, 2015). Dengan memanfaatkan teknologi ini, diharapkan jumlah kecelakaan yang diakibatkan oleh kelalaian manusia dapat berkurang hingga $80 \%$ (Thomas, 2016).

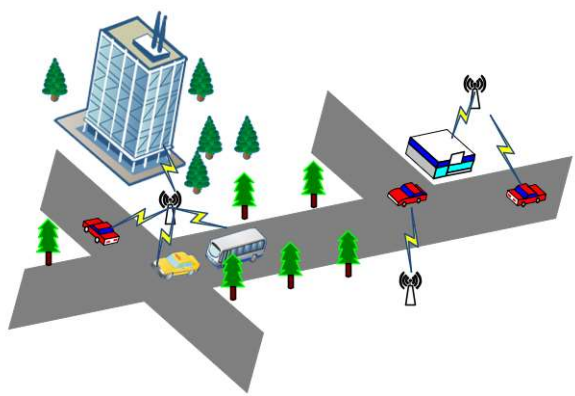

Gambar 1. Skema V2I

Dengan kondisi kendaraan yang bergerak, maka kondisi lingkungan yang dilewati pun akan berubah. Hal tersebut berpengaruh terhadap level noise yang diterima (Skrucany, dkk, 2017). Noise yang tinggi akan menyebabkan kemungkinan diterimanya bit error oleh receiver semakin tinggi (Pandey, dkk, 2013). Hal tersebut menyebabkan semakin tingginya nilai Signal to Noise Ratio (SNR) yang dibutuhkan untuk menjaga nilai errortetap berada pada level yang diizinkan. Salah satu strategi untuk mengakomodasi hal tersebut adalah dengan menggunakan skema modulasi yang berbeda mengikuti kondisi noise yang lingkungan (Eska, 2018). Semakin tinggi skema modulasi maka semakin tinggi nilai SNR yang dibutuhkan (Dangi \& Porwal, 2015). Hal tersebut berakibat pada semakin rendahnya level noise yang diizinkan. Namun keuntungan dari skema tersebut adalah semakin banyak informasi yang dapat dibawa oleh satu simbol (Singya, dkk, 2021).

Modulasi adaptif merupakan sebuah teknologi yang memungkinkan sistem untuk memilih skema modulasi yang paling baik sesuai dengan kondisi kanal (Masood, 2013). Saat kanal dalam kondisi bagus atau nilai noise rendah maka modulasi dengan data rate lebih tinggi dapat digunakan. Sedangkan saat kondisi kanal sedang buruk maka modulasi dengan data rate lebih rendah digunakan untuk menghindari terjadinya packet drop yang tinggi. Dengan mengimplementasikan skema modulasi adaptif, maka penggunaan bandwidth dapat dioptimalkan dan level sensitifitas terhadap perubahan lingkungan dapat diturunkan (Novfitri, dkk, 2018). Dengan demikian kualitas koneksi dapat dijaga walaupun kondisi lingkungan yang dilewati berubah-ubah.

Reinforcement learning merupakan bagian dari machine learning di mana learning process terjadi ketika agen berinteraksi dengan lingkungan (Ravinchandiran, 2018). Tidak seperti 
machine learning yang membutuhkan dataset untuk proses training, pada reinforcement learning agen akan mengeksplorasi lingkungannya dan membuat keputusan berdasarkan nilai reward dan punishment yang diberikan ketika agen melakukan suatu aksi (Lowe \& Ziemke, 2013). Setelah proses tria/ dan error, agen akan mempelajari aksi apa yang harus dilakukan untuk mendapatkan reward dengan nilai tertinggi (Sutton \& Barto, 2015). Sehingga agen akan memiliki kecenderungan untuk mengambil aksi tersebut jika berada pada suatu kondisi tertentu.

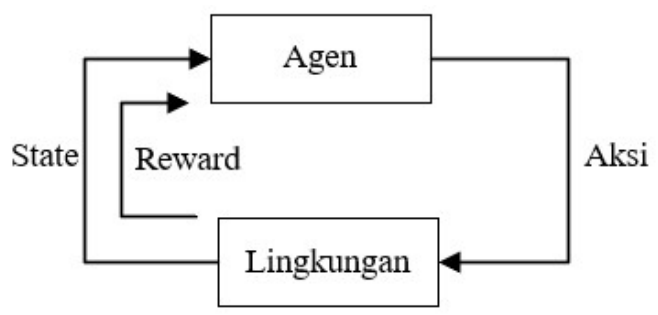

Gambar 2. Reinforcement Learning Loop

Epsilon greedy merupakan salah satu algoritma yang digunakan untuk learning process. Algoritma ini menyeimbangkan proses eksploitasi dan eksplorasi berdasarkan nilai epsilon (dos Santos Mignon \& de Azevedo da Rocha, 2017). Ketika agen melakukan eksplorasi lingkungan, agen akan mengambil aksi acak tanpa mempedulikan nilai reward atau punishment yang didapatkan. Sedangkan ketika agen berada dalam mode eksploitasi, maka agen akan melakukan aksi yang memberikan nilai reward tertinggi. Epsilon dalam hal ini merupakan parameter yang menentukan apakah agen akan melakukan eksplorasi atau eksploitasi (Nieuwdorp, 2017).

Pada penelitian ini dilakukan implementasi algoritma epsilon-greedy pada reinforcement learning sebagai pembuat keputusan untuk pemilihan skema modulasi pada V2I. Pada skema ini, infrastruktur bertindak sebagai pengirim ( Transmitter/Tx) yang memiliki kemampuan untuk mengubah skema modulasi. Sementara itu kendaraan yang bergerak merupakan penerima yang juga difungsikan sebagai agen. Model kanal Additive White Gaussian Noise (AWGN) digunakan untuk menentukan kondisi lingkungan yang dilewati kendaraan. Pada (Rochmatika, dkk, 2018) diusulkan Binary Phase Shift Keying (BPSK), Quadrature Phase Shift Keying (QPSK), dan 16-Quadrature Amplitude Modulation (16-QAM) sebagai modulasi untuk skema modulasi adaptif. Namun pada model kanal AWGN probabilitas error untuk BPSK dan QPSK tidak memiliki perbedaan pada perhitungannya. Sehingga penggunaan kedua modulasi tersebut tidak dapat digunakan untuk membedakan kondisi noise pada lingkungan. Oleh karena itu pada penelitian ini diusulkan penggunaan QPSK, 8PSK, dan 16-QAM sebagai skema modulasi untuk membedakan kondisi noise pada lingkungan.

Struktur paper ini adalah sebagai berikut, pada bagian pendahuluan dipaparkan ide dasar mengenai paper ini. Di bagian kedua dijelaskan mengenai pengimplementasian algoritma epsilon-greedy untuk skema modulasi adaptif pada V2I. Di bagian selanjutnya dijelaskan mengenai hasil yang didapat. Di bagian terakhir diambil kesimpulan mengenai penelitian ini.

\section{METODE}

Berdasarkan (Sassi, dkk, 2012), nilai maksimum bit error yang diperbolehkan untuk sistem komunikasi pada kendaraan adalah $10^{-3}$. Dengan menggunakan model kanal AWGN dan nilai $10^{-3}$ sebagai threshold probabilitas error, nilai Eb/No dikalkulasi sebagai dasar untuk mengkategorikan level noise menjadi low, medium, dan high. QPSK, 8PSK, dan 16-QAM 
digunakan untuk skema modulasi adaptif dengan level noise lingkungan sebagai penentunya. Skema modulasi yang lebih tinggi akan dimaksimalkan untuk kondisi lingkungan dengan level noise yang rendah. Sedangkan skema modulasi dengan data rate yang lebih rendah digunakan untuk lingkungan dengan level noise yang tinggi.

Setelah skema modulasi ditentukan, selanjutnya dilakukan implementasi epsilon-greedy pada reinforcement learning. Untuk mengasumsikan kondisi kendaraan bergerak melewati lingkungan yang memiliki level noise yang berbeda, simulasi dilakukan secara episodik dengan jumlah episode sebanyak 1000 kali. Hal tersebut digunakan untuk menggambarkan kendaraan yang bergerak melewati 1000 lingkungan yang berbeda-beda level noise-nya. Berdasarkan (Novfitri, dkk, 2018), rekomendasi kecepatan kendaraan untuk simulasi adalah 44.43 hingga 88.8 meter per jam.

\subsection{Menentukan Nilai Eb/No}

Parameter Energy per Bit to Spectral Noise Density (Eb/No) digunakan untuk membedakan kondisi setiap lingkungan. Untuk menghitung nilai Eb/No, Persamaan (1) digunakan untuk mengubah fungsi Q menjadi fungsi error (erfc) (Bliss \& Govindasamy, 2013).

$$
Q(x)=\frac{1}{2} \operatorname{erfc}\left(\frac{x}{\sqrt{2}}\right)
$$

Persamaan (2) digunakan untuk menghitung probabilitas errorpada modulasi QPSK (Ippolito Jr., 2017).

$$
P_{b}=Q\left(\sqrt{\frac{2 E_{b}}{N_{o}}}\right)
$$

Dengan memodifikasi Persamaan (2) dengan Persamaan (1), maka didapatkan persamaan untuk menghitung probabilitas error pada modulasi QPSK adalah:

$$
P_{b}=\frac{1}{2} \operatorname{erfc}\left(\sqrt{\frac{E_{b}}{N_{0}}}\right)
$$

Persamaan (4) digunakan untuk menghitung probabilitas error pada 8PSK dengan fungsi Q (Sighal, dkk, 2013).

$$
P_{b}=\frac{1}{\log _{2} M} 2 Q\left(\sqrt{2 \frac{E_{b}}{N_{0}} \log _{2} M} \sin \frac{\pi}{M}\right)
$$

Dengan memodifikasi Persamaan (4) dengan Persamaan (1), maka persamaan untuk menghitung probabilitas error 8PSK menjadi:

$$
P_{b}=\frac{1}{3} \operatorname{erfc}\left(\sqrt{3 \frac{E_{b}}{N_{0}}} \sin \left(\frac{180}{8}\right)^{o}\right)
$$


Berdasarkan (Oyetola, dkk, 2018), untuk menghitung probabilitas error 16-QAM, digunakan Persamaan (6).

$$
P_{b}=\frac{4}{\log _{2} M}\left(1-\frac{1}{\sqrt{M}}\right) Q\left(\sqrt{\frac{3 \log _{2} M}{M-1} \frac{E_{b}}{N_{0}}}\right)
$$

Dengan mengubah fungsi Q pada Persamaan (6) menjadi fungsi error pada Persamaan (1), maka persamaan untuk menghitung probabilitas error 16-QAM menjadi :

$$
P_{b}=\frac{3}{8} \operatorname{erfc}\left(\sqrt{\frac{2}{5} \frac{E_{b}}{N_{0}}}\right)
$$

Dengan menggunakan Persamaan (3), (5), dan (7) dengan nilai $\mathrm{Pb}=10^{-3}$, maka didapatkan nilai threshold Eb/No untuk setiap modulasi adalah: $6.78 \mathrm{~dB}$ untuk QPSK, $10 \mathrm{~dB}$ untuk 8PSK, dan $10.52 \mathrm{~dB}$ untuk 16-QAM. Tabel 1 merangkum nilai Eb/No untuk setiap modulasi dalam satuan desibel $(\mathrm{dB})$

Tabel 1. Nilai Threshold Eb/No Setiap Modulasi

\begin{tabular}{|l|l|}
\hline Modulasi & $\mathbf{E}_{\mathbf{b}} / \mathbf{N}_{\mathbf{o}}(\mathbf{d B})$ \\
\hline QPSK & 6.78 \\
\hline 8PSK & 10 \\
\hline 16-QAM & 10.52 \\
\hline
\end{tabular}

Berdasarkan hasil perhitungan, semakin tinggi skema modulasi maka semakin tinggi nilai Eb/No yang dibutuhkan untuk menjaga probabilitas error tidak melebihi $10^{-3}$. Dengan asumsi nilai Eb konstan maka dibutuhkan level noise yang lebih rendah agar probabilitas error terjaga pada nilai $10^{-3}$.

\subsection{Menentukan Threshold untuk Setiap Lingkungan}

Dengan menggunakan nilai pada Tabel 1 sebagai acuan threshold Eb/No, kondisi lingkungan dikategorikan menjadi tiga kondisi. Ketika nilai Eb/No kurang dari $6.78 \mathrm{~dB}$, lingkungan diasumsikan berada pada kondisi high noise. Sementara itu saat Eb/No berada di antara 6.78 dan $10 \mathrm{~dB}$ kondisi lingkungan diasumsikan berada pada kondisi medium noise. Sedangkan saat $\mathrm{Eb} /$ No berada pada nilai melebihi $10 \mathrm{~dB}$ diasumsikan lingkungan berada pada kondisi low noise. Dengan demikian nilai Eb/No untuk setiap kondisi lingkungan noise dapat dirangkum seperti yang ditunjukkan pada Tabel 2 .

Tabel 2. Nilai Eb/No Setiap Lingkungan

\begin{tabular}{|l|l|}
\hline \multicolumn{1}{|c|}{ Noise } & \multicolumn{1}{c|}{ Nilai (dB) } \\
\hline High & $\mathrm{Eb} / \mathrm{No}<6.78$ \\
\hline Medium & $6.78 \leq \mathrm{Eb} / \mathrm{No} \leq 10$ \\
\hline Low & $\mathrm{Eb} / \mathrm{No}>10$ \\
\hline
\end{tabular}

\subsection{Menentukan Skema Modulasi Setiap Lingkungan}

Setelah mendefiniskan nilai Eb/No untuk setiap kondisi lingkungan, langkah selanjutnya adalah menentukan skema modulasi untuk setiap lingkungan dengan menggunakan Tabel 1 dan 2 sebagai acuan. 
Saat Eb/No berada pada nilai kurang dari $6.78 \mathrm{~dB}$, threshold Eb/No hanya terpenuhi untuk modulasi QPSK. Oleh karena itu pada kondisi lingkungan high noise hanya skema modulasi QPSK yang diizinkan untuk dipergunakan. Ketika Eb/No berada pada antara 6.78 dan $10 \mathrm{~dB}$, nilai tersebut memenuhi threshold QPSK dan 8PSK. Oleh karena itu ketika level noise berada pada kondisi medium noise, skema modulasi yang diperbolehkan untuk digunakan adalah 8PSK dan 16-QAM. Sedangkan saat Eb/No berada di atas $10 \mathrm{~dB}$ maka threshold untuk skema modulasi QPSK, 8PSK, dan 16-QAM terpenuhi. Oleh karena itu saat noise level berada pada kondisi low noise, ketiga skema modulasi diperbolehkan untuk digunakan. Tabel 3 menunjukkan mapping skema modulasi yang diperbolehkan untuk setiap kondisi lingkungan.

Tabel 3. Mapping Skema Modulasi Setiap Lingkungan

\begin{tabular}{|c|c|c|c|c|}
\hline & \multicolumn{3}{|c|}{ Skema Modulasi } \\
\hline & & 16-QAM & 8PSK & QPSK \\
\hline \multirow{3}{*}{ Noise } & High & $\mathrm{X}$ & $X$ & V \\
\hline & Medium & $X$ & V & V \\
\hline & Low & $\mathrm{V}$ & V & V \\
\hline \multicolumn{5}{|c|}{$\begin{array}{l}\text { Keterangan: } \\
X \quad \text { tidak }\end{array}$} \\
\hline
\end{tabular}

Pada kondisi low noise dan medium noise, ada lebih dari satu skema modulasi yang diperbolehkan untuk digunakan. Oleh karena itu prioritas diberikan untuk mengontrol pemilihan skema modulasi. Skema modulasi dengan data rate yang lebih tinggi diberikan nilai prioritas yang lebih tinggi dibandingkan dengan skema modulasi dengan data rate yang lebih rendah. Sehingga tanda "V" pada Tabel 3 diubah menjadi nilai prioritas di mana semakin kecil angkanya maka semakin tinggi prioritas penggunaan.

Tabel 4. Mapping Prioritas Skema Modulasi

\begin{tabular}{|c|c|c|c|c|}
\hline \multicolumn{2}{|c|}{} & \multicolumn{3}{|c|}{ Skema Modulasi } \\
\cline { 3 - 5 } & 16-QAM & 8PSK & QPSK \\
\hline \multirow{3}{*}{ Noise } & High & $\mathrm{X}$ & $\mathrm{X}$ & 1 \\
\cline { 2 - 5 } & Medium & $\mathrm{X}$ & 1 & 2 \\
\cline { 2 - 5 } & Low & 1 & 2 & 3 \\
\hline
\end{tabular}

$\begin{array}{ll}\text { Keterangan: } \\ X & \text { : tidak diperbolehkan } \\ 1 & \text { : prioritas pertama/tertinggi } \\ 2 & \text { : prioritas kedua } \\ 3 & \text { : prioritas ketiga/terendah }\end{array}$

Pada kondisi low noise, penggunaan skema modulasi 16-QAM lebih diprioritaskan dibandingkan penggunaan skema modulasi 8PSK dan penggunaan skema modulasi QPSK merupakan prioritas terakhir. Hal tersebut disebabkan 16-QAM memiliki data rate yang paling tinggi dibanding dua skema modulasi lainnya. Hal tersebut sejalan dengan kondisi lingkungan pada medium noise. 8PSK diberikan prioritas yang lebih tinggi karena memiliki data rate yang lebih tinggi dibandingkan QPSK.

\subsection{Implementasi Reinforcement Learning}

Reinforcement learning melakukan proses learning berdasarkan prinsip reward dan punishment. Reward diberikan jika agen mengambil aksi yang benar dan punishment jika aksi yang diambil salah. Dengan menggunakan Tabel 4 sebagai acuan, nilai rewardand punishment ditentukan. 
Pada kondisi high noise, skema modulasi yang boleh dipergunakan hanya QPSK. Maka jika agen mengambil aksi untuk menggunakan skema modulasi yang lain, maka agen akan diberikan punishment. Hal serupa juga dilakukan pada kondisi medium noise. Punishmentakan diberikan kepada agen jika skema modulasi 16-QAM dipilih. Pada kondisi noise yang sama, 8PSK memiliki prioritas lebih tinggi dibandingkan QPSK. Oleh karena itu reward untuk agen jika memilih 8PSK akan lebih besar dibandingkan dengan QPSK. Pada kondisi low noise, reward yang paling besar akan diberikan jika agen memilih skema modulasi 16-QAM sedangkan jika QPSK yang dipilih maka agen akan diberikan reward dengan nilai yang paling kecil. Tabel 5 menampilkan nilai reward dan punishment untuk setiap skema modulasi di masing-masing kondisi noise.

Tabel 5. Nilai Reward Dan Punishment

\begin{tabular}{|c|c|c|c|c|}
\hline \multicolumn{2}{|c|}{} & \multicolumn{3}{|c|}{ Skema Modulasi } \\
\cline { 3 - 5 } & 16-QAM & 8PSK & QPSK \\
\hline \multirow{3}{*}{ Noise } & High & 0 & 0 & 0.9 \\
\cline { 2 - 5 } & Medium & 0 & 0.9 & 0.3 \\
\cline { 2 - 5 } & Low & 0.9 & 0.3 & 0.1 \\
\hline
\end{tabular}

Nilai punishment yang diberikan adalah 0 . Sehingga ketika agen memilih skema modulasi 16QAM atau 8PSK pada kondisi lingkungan dengan high noise atau 16-QAM pada kondisi medium noise maka agen akan diberikan nilai 0 untuk aksi tersebut. Sedangkan jika agen memilih skema modulasi 8PSK saat kondisi medium noise atau 16-QAM pada kondisi low noise maka agen akan mendapatkan reward yang tinggi. Dengan hal tersebut maka agen akan belajar aksi apa yang dapat memberikan nilai terbaik saat berada di suatu kondisi. Sehingga agen memiliki kecenderungan untuk mengambil aksi terbaik setiap kali berada di kondisi tertentu.

Pada algoritma epsilon greedy, agen berada pada mode eksplorasi atau eksploitasi ditentukan oleh nilai epsilon. Untuk mengontrol agen agar dapat memasuki mode ekplorasi atau eksploitasi, sebuah nilai acak akan dibangkitkan. Jika nilai acak lebih besar dari epsilon, maka agen akan berada pada mode eksploitasi. Pada mode ini agen akan mengambil aksi yang memiliki nilai reward tertinggi. Sedangkan jika nilai acak yang dibangkitkan lebih rendah dari epsilon, maka agen akan berada pada mode eksplorasi. Pada mode ini agen akan mengambil aksi secara acak. Gambar 3 mengilustrasikan cara kerja algoritma epsilon greedy.

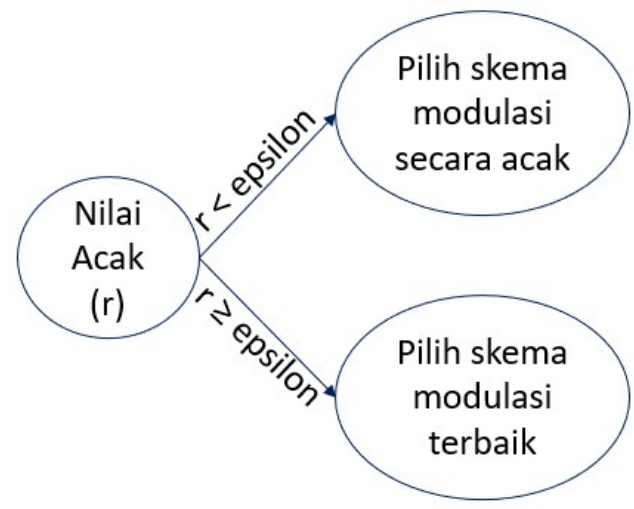

\section{Gambar 3. Cara Kerja Algoritma Epsilon Greedy}

Nilai acak ( $r$ ) akan dibangkitkan dengan nilai antara 0 dan 1 . Angka ini kemudian dibandingkan dengan nilai epsilon. Jika $r$ bernilai lebih kecil dari epsilon maka agen akan memilih skema modulasi secara acak apapun kondisi lingkungannya. Agen bisa mendapatkan reward atau 
punishment tergantung skema modulasi yang dipilihnya. Sementara itu ketika $r$ yang dibangkitkan bernilai lebih besar dari epsilon maka agen akan memilih skema modulasi terbaik berdasarkan nilai pada Tabel 5. Untuk mengetahui pengaruh epsilon terhadap hasil pengambilan keputusan maka pada simulasi akan digunakan nilai epsilon yang berbeda-beda. Nilai epsilon yang digunakan pada simulasi adalah $0.1,0.2,0.3,0.4$, dan 0.5 .

Berikut ini adalah alur simulasi yang dibuat. Untuk menyimulasikan kendaraan yang bergerak melalui berbagai kondisi lingkungan maka algoritma dibuat dengan situasi episodik. Setiap satu episode, kendaraan melalui satu kondisi lingkungan. Program di-loop sebanyak seribu kali untuk menyimulasikan kendaraan yang bergerak melewati seribu kondisi lingkungan dalam sekali perjalanan. Flowchart di bawah ini menunjukkan algoritma yang dibuat.

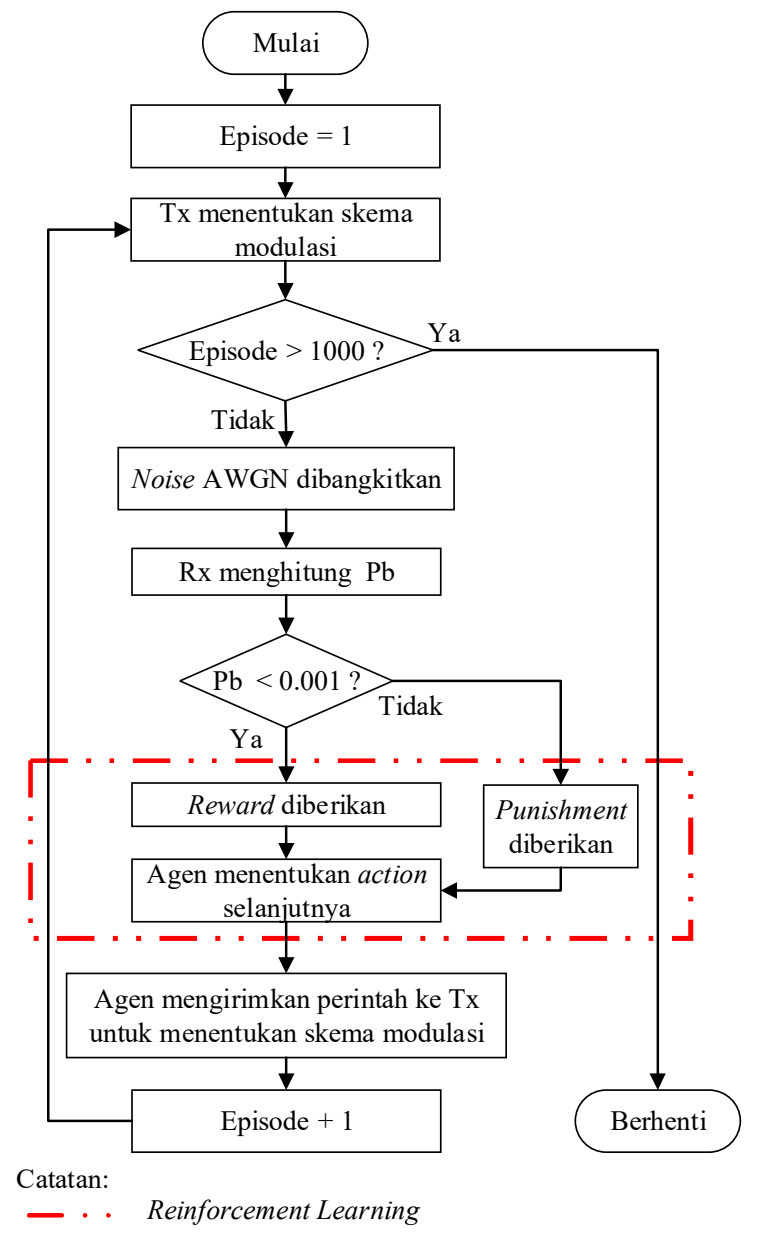

Gambar 4. Alur Simulasi

Pada episode 1, pengirim atau Tx secara acak menentukan skema modulasi yang digunakan. Kemudian program melakukan perhitungan jumlah episode. Jika episode lebih dari seribu, maka simulasi akan dihentikan. Jika episode masih bernilai kurang dari seribu, maka simulasi akan dilanjutnya ke tahap selanjutnya. Noise AWGN dibangkitkan untuk mensimulasikan kondisi lingkungan yang dilewati oleh kendaraan dengan nilai yang termasuk ke dalam level low, medium, atau high noise. Kendaraan sebagai penerima kemudian menghitung nilai $\mathrm{Pb}$ yang diterima. Jika probabilitas error lebih dari $10^{-3}$, maka kendaraan yang juga bertindak sebagai agen akan diberikan punishment. Sedangkan jika nilai probabilitas error kurang dari 
$10^{-3}$ maka reward akan diberikan dengan nilai seperti yang ditunjukkan oleh Tabel 5 . Selanjutnya agen dengan reinforcement learning akan menentukan skema modulasi apa yang seharusnya digunakan saat berada pada kondisi tersebut. Selanjutnya agen mengirimkan perintah ke Tx untuk menggunakan skema modulasi seperti yang diperintahkan oleh agen. Hal tersebut dilakukan secara terus menerus hingga episode berjumlah seribu. Setiap seribu loop, nilai epsilon diubah mulai dari 0.1 hingga 0.5 . Setelah simulasi selesai, selanjutnya dilakukan analisis terhadap hasil yang didapatkan.

\section{HASIL DAN PEMBAHASAN}

Pada bagian ini akan dibahas hasil simulasi dengan nilai epsilon yang bervariasi dari 0.1 hingga 0.5. Hasil simulasi yang ditampilkan menggunakan empat skenario. Skenario pertama kendaraan bergerak melewati lingkungan low, medium, dan high noise. Pada skenario kedua kendaraan melewati lingkungan low noise. Skenario selanjutnya, kendaraan melewati lingkungan medium noise. Pada skenario terakhir, kendaraan melewati lingkungan high noise.

\subsection{Hasil Simulasi Seluruh Kondisi Noise}

Gambar 5 menunjukkan hasil simulasi untuk seluruh kondisi noise. Dari grafik dapat dilihat bahwa agen mendapatkan punishment dengan nilai 0 dan reward yang bervariasi, antara 0.1 , 0.3 , dan 0.9 .

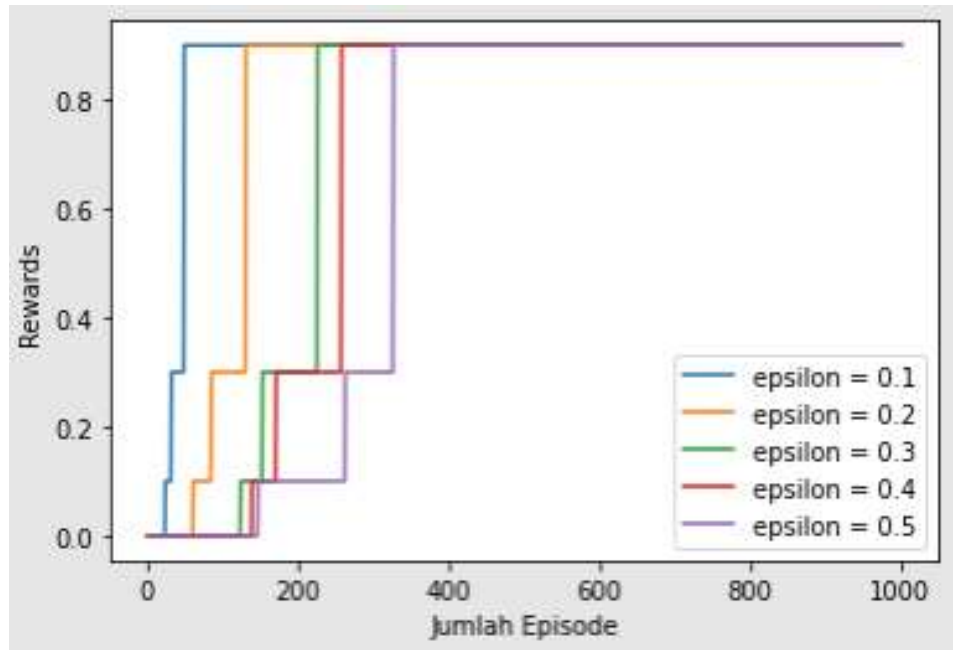

Gambar 5. Hasil Simulasi Seluruh Level Noise

Saat epsilon bernilai 0.1 , agen mendapatkan nilai 0 sebanyak 23 kali, rewards 0.1 sebanyak 8 kali, reward 0.3 sebanyak 17 kali, dan reward 0.9 sebanyak 952 kali. Ketika epsilon bernilai 0.2 agen mendapatkan punishment 0 sebanyak 60 kali, reward 0.1 sebanyak 24 kali, reward 0.3 sebanyak 46 kali, dan reward 0.9 sebanyak 870 kali. Sementara itu saat epsilon bernilai 0.3 , punishment bernilai 0 didapatkan agen sebanyak 123 kali, reward 0.1 sebanyak 29 kali, reward 0.3 sebanyak 73 kali, dan reward 0.9 didapatkan sebanyak 775 kali. Sedangkan saat epsilon bernilai 0.4 , agen mendapatkan punishment sebanyak 138 kali, reward 0.1 sebanyak 32 kali, reward 0.3 sebanyak 87 kali, dan reward 0.9 sebanyak 743 kali. Tabel 6 merangkum jumlah reward dan punishment yang didapatkan oleh agen. 
Tabel 6. Jumlah Reward Dan Punishment yang Didapatkan Agen

\begin{tabular}{|c|c|c|c|c|c|}
\hline \multicolumn{2}{|c|}{} & \multicolumn{4}{|c|}{ Rewards (jumlah episode) } \\
\cline { 3 - 6 } \multicolumn{1}{|c|}{} & $\mathbf{0 . 9}$ & $\mathbf{0 . 3}$ & $\mathbf{0 . 1}$ & $\mathbf{0}$ \\
\hline \multirow{4}{*}{ Epsilon } & $\mathbf{0 . 1}$ & 952 & 17 & 8 & 23 \\
\cline { 2 - 6 } & $\mathbf{0 . 2}$ & 870 & 46 & 24 & 60 \\
\cline { 2 - 6 } & $\mathbf{0 . 3}$ & 775 & 73 & 29 & 123 \\
\cline { 2 - 6 } & $\mathbf{0 . 4}$ & 743 & 87 & 32 & 138 \\
\cline { 2 - 6 } & $\mathbf{0 . 5}$ & 674 & 64 & 116 & 146 \\
\hline
\end{tabular}

Dari hasil simulasi didapatkan semakin tinggi nilai epsilon maka jumlah punishment yang didapatkan agen semakin banyak dan reward tertinggi semakin sedikit. Hal tersebut disebabkan oleh semakin besarnya batas antara mode eksplorasi dan eksploitasi. Ketika nilai epsilon semakin besar maka agen akan semakin sering berada pada mode eksplorasi. Sehingga semakin sering agen memilih skema modulasi secara acak tanpa mempedulikan kondisi lingkungan.

\subsection{Hasil Simulasi Lingkungan Low Noise}

Gambar 6 menunjukkan hasil simulasi pada kondisi low noise. Pada simulasi ini agen melewati 1000 tempat dengan nilai noise yang berbeda namun termasuk ke dalam kondisi lingkungan low noise. Berdasarkan Tabel 3, pada kondisi low noise agen diperbolehkan menggunakan ketiga skema modulasi. Namun lebih diprioritaskan untuk menggunakan skema modulasi yang memiliki data rate tertinggi, sesuai dengan Tabel 5, yaitu 16-QAM.

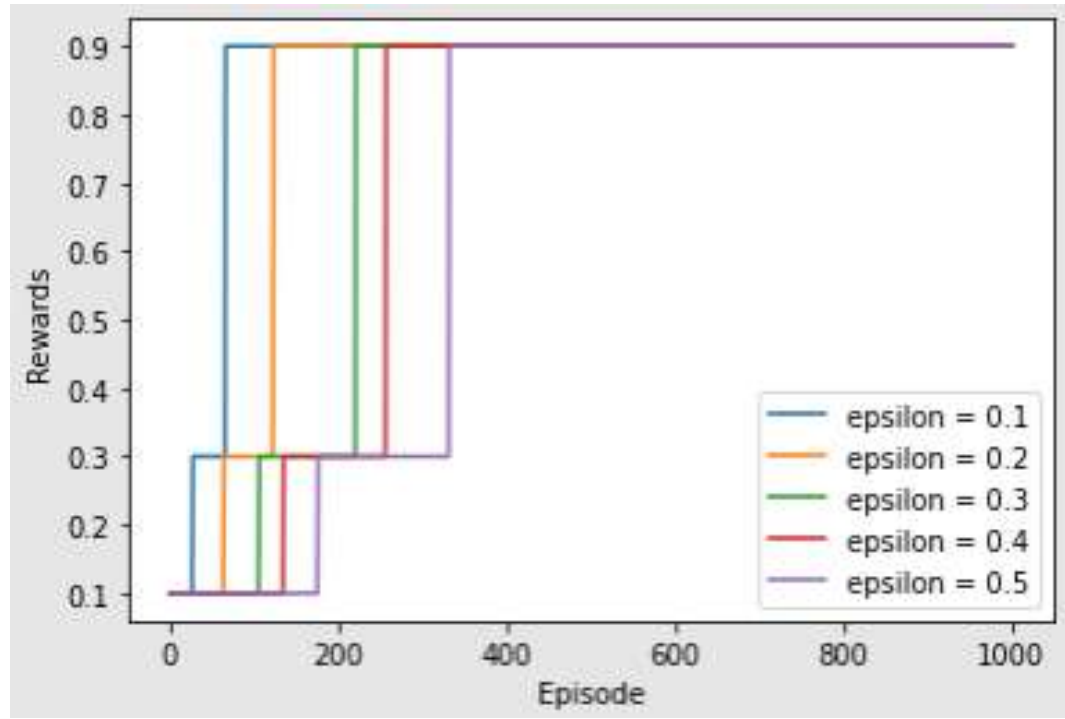

Gambar 6. Hasil Simulasi Kondisi Low Noise

Dari grafik dapat dilihat bahwa semakin tinggi nilai epsilon, semakin sering agen mengambil aksi yang tidak memberikan nilai reward tertinggi. Tabel 7 menunjukkan berapa kali reward yang didapatkan oleh agen dalam 1000 kali percobaan dengan nilai epsilon yang berbeda. 
Tabel 7. Reward yang didapatkan Agen dalam 1000 Episode pada Kondisi Low Noise

\begin{tabular}{|c|c|c|c|c|}
\hline & \multicolumn{3}{|c|}{ Rewards (jumlah episode) } \\
\hline & & 0.9 & 0.3 & 0.1 \\
\hline \multirow{5}{*}{ Epsilon } & 0.1 & 935 & 39 & 26 \\
\hline & 0.2 & 878 & 59 & 63 \\
\hline & 0.3 & 780 & 115 & 105 \\
\hline & 0.4 & 744 & 122 & 134 \\
\hline & 0.5 & 669 & 156 & 175 \\
\hline
\end{tabular}

Dari hasil simulasi pada kondisi low noise menunjukkan hasil yang mirip dengan yang didapatkan pada simulasi dengan kondisi lingkungan yang berbeda-beda. Pada kondisi low noise, agen semakin sering mengambil aksi memilih modulasi dengan data rate yang lebih rendah ketika nilai epsilon semakin tinggi. Saat epsilon 0.1 , agen tidak memilih 16-QAM sebanyak 65 kali. Saat epsilon bernilai 0.2 skema modulasi tidak dipilih sebanyak 122 kali dan terus meningkat hingga pada epsilon 0.5 agen tidak memilih skema modulasi 16-QAM sebanyak 331 kali. Hal tersebut terjadi karena gap antara mode eksplorasi dan eksploitasi semakin besar. Sehingga agen akan semakin sering memilih skema modulasi secara acak dibandingkan memilih skema modulasi terbaik.

\subsection{Hasil Simulasi Lingkungan Medium Noise}

Gambar 7 menunjukkan hasil simulasi dengan 1000 kali percobaan pada kondisi lingkungan medium noise. Seperti pada kondisi low noise, pada simulasi ini kendaraan diasumsikan melewati 1000 tempat dengan kondisi AWGN yang berbeda namun masih termasuk dalam kondisi medium noise.

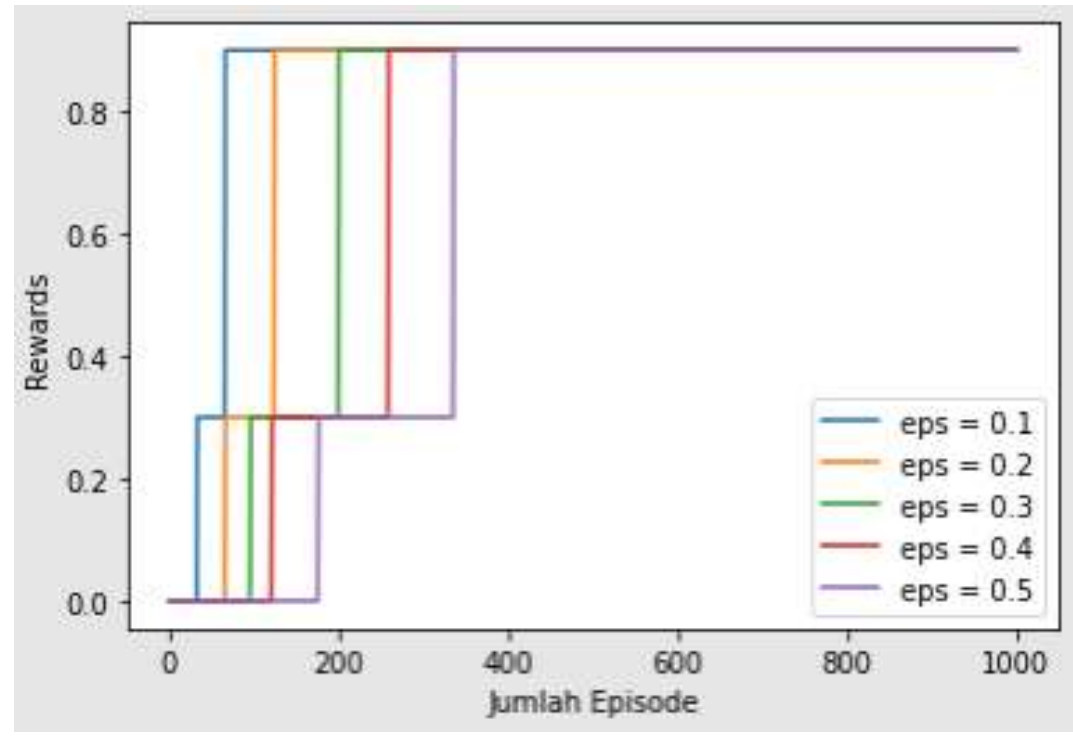

Gambar 7. Hasil Simulasi Kondisi Medium Noise

Dari grafik dapat dilihat bahwa hasil yang didapatkan mirip dengan Gambar dan Gambar . Semakin tinggi nilai epsilon, semakin banyak jumlah episode di mana agen tidak memilih skema modulasi terbaik. Tabel 8 menunjukkan jumlah reward dan punishment untuk nilai yang berbeda selama 1000 kali simulasi. 
Algoritma Epsilon Greedy pada Reinforcement Learning untuk Modulasi Adaptif Komunikasi

Vehicle to Infrastructure (V2I)

Tabel 8. Reward yang didapatkan Agen dalam 1000 Episode pada Kondisi Medium Noise

\begin{tabular}{|c|c|c|c|c|}
\hline & \multicolumn{3}{|c|}{ Rewards (jumlah episode) } \\
\hline & & 0.9 & 0.3 & $\mathbf{0}$ \\
\hline \multirow{5}{*}{ Epsilon } & 0.1 & 935 & 33 & 32 \\
\hline & 0.2 & 877 & 58 & 65 \\
\hline & 0.3 & 801 & 104 & 95 \\
\hline & 0.4 & 742 & 138 & 120 \\
\hline & 0.5 & 665 & 160 & 175 \\
\hline
\end{tabular}

Dari Tabel di atas diketahui bahwa saat epsilon 0.1 agen mendapatkan reward maksimal sebanyak 935 kali dan terus menurun hingga pada epsilon bernilai 0.5 agen hanya 665 kali mendapatkan reward tertinggi.

Berdasarkan Tabel 3 saat kondisi medium noise, agen hanya diperbolehkan menggunakan skema modulasi 8PSK dan QPSK. Namun dari hasil simulasi yang ditunjukan pada Tabel 8 didapatkan hasil bahwa agen juga memilih skema modulasi 16-QAM. Sehingga mendapatkan punishment berupa nilai 0 . Hal tersebut terjadi karena saat epsilon semakin tinggi maka probabilitas agen berada pada mode eksplorasi pun semakin besar. Sehingga agen memilih skema modulasi secara acak tanpa mempertimbangkan apakah akan mendapatkan reward atau punishment.

\subsection{Hasil Simulasi Lingkungan High Noise}

Gambar 8 menunjukkan hasil simulasi dari 1000 kali percobaan pemilihan skema modulasi oleh agen pada kondisi lingkungan high noise.

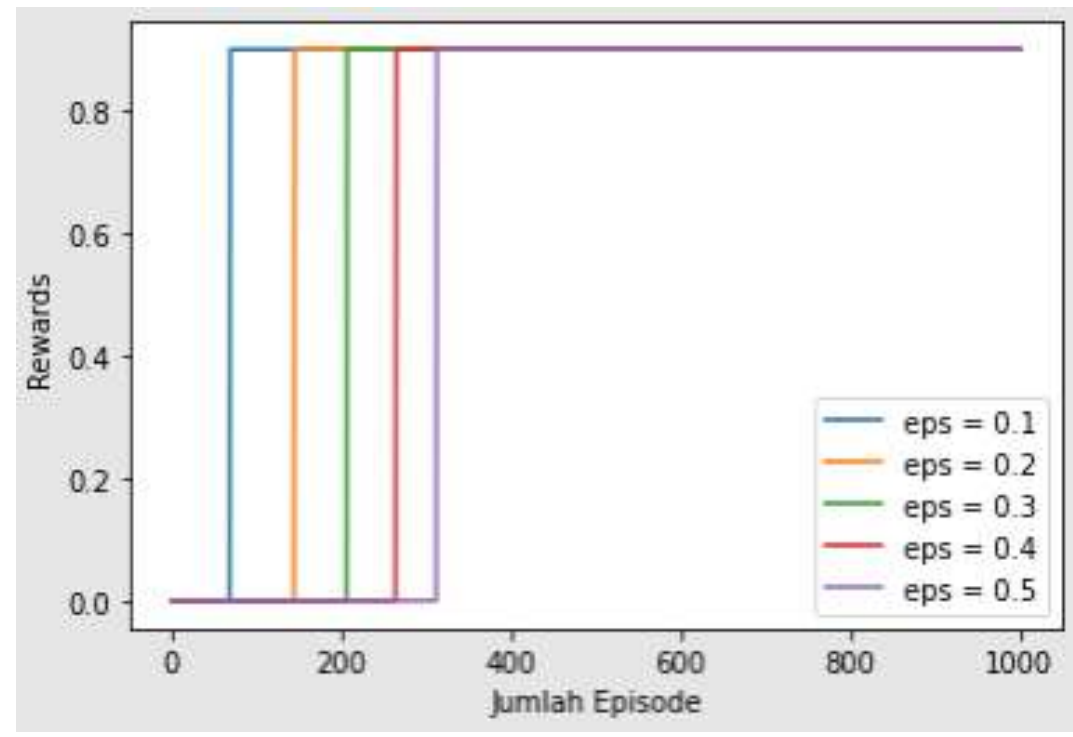

Gambar 8. Hasil Simulasi Kondisi High Noise

Dari gambar didapatkan hasil yang menyerupai dengan grafik pada Gambar . Agen mendapatkan punishment yang semakin banyak saat nilai epsilon semakin tinggi. Tabel 9 merangkum jumlah reward dan punishment yang didapatkan oleh agen. 
Tabel 9. Reward yang Didapatkan Agen dalam 1000 Episode pada Kondisi High Noise

\begin{tabular}{|c|c|c|c|}
\hline & \multicolumn{2}{|c|}{ Rewards (jumlah episode) } \\
\hline & & 0.9 & 0.3 \\
\hline \multirow{5}{*}{ Epsilon } & 0.1 & 932 & 68 \\
\hline & 0.2 & 856 & 144 \\
\hline & 0.3 & 794 & 206 \\
\hline & 0.4 & 736 & 264 \\
\hline & 0.5 & 688 & 312 \\
\hline
\end{tabular}

Berdasarkan Tabel 3, saat kondisi high noise agen hanya diperbolehkan memilih skema modulasi QPSK karena jika dua skema modulasi lain yang dipilih maka nilai probabilitas error akan melebihi $10^{-3}$. Hal tersebut dapat mengakibatkan tingginya packet drop. Namun dari Tabel di atas diketahui bahwa agen mendapatkan punishment sebanyak 144 kali saat kondisi epsilon 0.2 dan terus meningkat hingga mencapai 312 kali saat epsilon bernilai 0.5 . Hal tersebut disebabkan oleh semakin besarnya kemungkinan agen memilih skema modulasi secara acak saat nilai epsilon semakin tinggi.

\section{KESIMPULAN}

Dari hasil simulasi, reinforcement learning dengan algoritma epsilon greedy dapat diimplementasikan untuk skema modulasi adaptif pada V2I. Dengan kondisi nilai epsilon yang berbeda-beda mulai dari 0.1 hingga 0.5 didapatkan hasil bahwa semakin tinggi nilai epsilon maka semakin sering agen tidak memilih skema modulasi dengan reward tertinggi. Hal tersebut disebabkan semakin tinggi nilai epsilon, semakin sering agen memilih skema modulasi secara acak.

\section{DAFTAR RUJUKAN}

Bliss, D. W., \& Govindasamy, S. (2013). Adaptive Wireless Communications (MIMO Channels and Networks) (1st Editio). Cambridge University Press.

Cronin, B. (2015). Connected Vehicle Benefits. Bureau of Transportation Statistics. https://www.its.dot.gov/factsheets/pdf/ConnectedVehicleBenefits.pdf

Dangi, M., \& Porwal, M. K. (2015). Analyses of SNR Threshold for Minimum BER in Various Modulations Schemes and Development Of an Adaptive Modulation Scheme. IJISET International Journal of Innovative Science, Engineering \& Technology, 2(3), 139-142.

dos Santos Mignon, A., \& de Azevedo da Rocha, R. L. (2017). An Adaptive Implementation of $\varepsilon$-Greedy in Reinforcement Learning. Procedia Computer Science, 109, 1146-1151. https://doi.org/10.1016/j.procs.2017.05.431

Eska, A. C. (2018). Adaptive Modulation and Coding (AMC) around Building Environment for MS Communication at The Train. EMITTER International Journal of Engineering Technology, 6(2), 386-394. https://doi.org/10.24003/emitter.v6i2.279 
Halegoua, G. R. (2020). Smart Cities. The MIT Press.

Ippolito Jr., L. J. (2017). Satellite Communications Systems Engineering: Atmospheric Effects, Satellite Link Design and System Performance (2nd Editio). Wiley.

Lowe, R., \& Ziemke, T. (2013). Exploring the relationship of reward and punishment in reinforcement learning. 2013 IEEE Symposium on Adaptive Dynamic Programming and Reinforcement $\quad$ Learning 140-147. https://doi.org/10.1109/ADPRL.2013.6615000

Masood, R. F. (2013). Adaptive Modulation (QPSK, QAM). ArXiv Preprint ArXiv:1302.7145. http://arxiv.org/abs/1302.7145

Nieuwdorp, T. (2017). Dare to Discover: The Effect of the Exploration Strategy on an Agent's Performance. Radboud University Nijmegen.

Novfitri, A., Suryani, T., \& Suwadi. (2018). Performance Analysis of Vehicle-to-Vehicle Communication with Adaptive Modulation. 2018 Electrical Power, Electronics, Communications, Controls and Informatics Seminar (EECCIS), 187-191. https://doi.org/10.1109/EECCIS.2018.8692895

Oyetola, O. K., Okubanjo, A. A., Okandeji, A. A., Alao, P. O., Osifeko, M. O., \& Olasunkanmi, O. G. (2018). Symbol Error Probability Of 16-QAM System Over AWGN and Rayleigh Fading Channels. African Journal of Science \& Nature, 7, 29-39.

Pandey, R., Awasthi, A., \& Srivastava, V. (2013). Comparison between Bit Error Rate And Signal To Noise Ratio in OFDM Using LSE Algorithm. Conference on Advances in Communication and Control Systems 2013 (CAC2S 2013), 463-466.

Ravinchandiran, S. (2018). Hands-On Reinforcement Learning with Python. Packt Publishing Ltd.

Rochmatika, R. A., Suryani, T., \& Wirawan. (2018). Performance of Adaptive Modulation over Frequency Selective Fading Channel in VANET Environment. 2018 10th International Conference on Information Technology and Electrical Engineering (ICITEE), 400-405.

Sassi, A., Charfi, F., Kamoun, L., Elhillali, Y., \& Rivenq, A. (2012). OFDM Transmission Performance Evaluation in V2X Communication. International Journal of Computer Science Issues, 9(2), 141-148. http://arxiv.org/abs/1410.8039

Sighal, M., Agarwal, M., Trikha, M., \& Sharma, N. (2013). Bit Error Rate Performance of Gray Coded 8-PSK. MIT International Journal of Electronics and Communication Engineering, $3(1), 20-24$.

Singya, P. K., Shaik, P., Kumar, N., Bhatia, V., \& Alouini, M.-S. (2021). A Survey on HigherOrder QAM Constellations: Technical Challenges, Recent Advances, and Future Trends. 
IEEE Open Journal of the Communications Society, 1-1. https://doi.org/10.1109/OJCOMS.2021.3067384

Skrucany, T., Sarkan, B., FigluzTomasz, Synak, F., \& Vrabel, J. (2017). Measuring of noise emitted by moving vehicles. Dynamics of Civil Engineering and Transport Structures $\begin{array}{lllll}\text { and Wind } & \text { Engineering }\end{array}$ https://doi.org/10.1051/matecconf/2017107000

Sutton, R. S., \& Barto, A. G. (2015). Reinforcement Learning: An Introduction. The MIT Press. Thomas, B. (2016). Proposed rule would mandate vehicle-to-vehicle (V2V) communication on light vehicles, allowing cars to "talk" to each other to avoid crashes. National Highway Traffic Safety Information.

Wietfeld, C., \& Ide, C. (2015). Vehicle-to-infrastructure communications. In Vehicular Communications and Networks, (pp. 3-28). Elsevier. https://doi.org/10.1016/B978-178242-211-2.00001-5 